\title{
USO DA FARINHA DA CASCA DO MARACUJÁ AMARELO (PASSIFLORA EDULIS F. FLAVICARPA DEG. - FAMÍLIA PASSIFLORACEAE) NA FORMULAÇÃO DE MACARRÃO CASEIRO
}

\section{USE OF PASSIONFRUIT PEEL FLOUR (PASSIFLORA EDULIS F. FLAVICARPA DEG. - FAMILY PASSIFLORACEAE) IN HOMEMADE PASTA RECIPE.}

\author{
B. F. COSTA ${ }^{1}$; F. R. DE LIZ1; J. G. S. FERREIRA ${ }^{1}$; R. C. SANTOS ${ }^{1}$; T. H. \\ GONÇALVES $^{1}$; M. E. BALBI ${ }^{2}$
}

1 - Aluno do curso de farmácia da Universidade Federal do Paraná - UFPR

2 - Professora da disciplina de Bromatologia, Departamento de Farmácia, UFPR.

Autor para correspondência: bromatologia.ufpr@gmail.com

\section{RESUMO}

O presente trabalho teve como foco a elaboração de um macarrão adicionado de farinha de casca de maracujá, visando comparar os resultados da determinação de componentes nutricionais (umidade, proteínas, lipídios, fibras, minerais e carboidratos) com uma alimentação mais saudável. Os frutos foram obtidos na região metropolitana de Curitiba e o macarrão produzido de acordo com receita a base de farinha de trigo e ovos, sendo adicionada cerca de $7 \%$ de farinha de casca de maracujá. Os testes de determinação nutricional comprovaram uma boa quantidade de fibras no produto final, caracterizando assim uma possível alternativa para uma alimentação mais saudável. Também foi realizada avaliação das características sensoriais do produto, que apresentou resultados medianos, considerados suficientes para o que diz respeito a esse trabalho.

PALAVRAS-CHAVE: maracujá, macarrão, farinha da casca.

\section{ABSTRACT}

The present work sought the elaboration of a pasta added with passionfruit peel flour, fetching nutricional components data (humidity, protein, lipids, fibers, minerals and carbohydrates) with possible application sugar level reduction. The fruits were obtained in Curitiba's surroundings and the pasta made respecting the flour and eggs recipe, added nearly $7 \%$ of passionfruit peel flour. The nutritional determination tests showed a suitable fibers value to characterize a good decrease in sugar level in future buyers. A sensorial test was also realized, that had adequate results according to this work's goals.

KEY WORDS: passionfruit, pasta, peel flour

\section{INTRODUÇÃO}

O maracujá-amarelo (Passiflora edulis f. flavicarpa deg), família Passifloraceae, é um fruto abundante no setor alimentício brasileiro, caracterizado por seu baixo custo e alta versatilidade na formulação de receitas, com sua polpa sendo usada principalmente na confecção de sucos e doces. Entretanto, boa parte de sua massa total é simplesmente 
descartada como resíduo, tendo como consequências exalação de odores fortes (SOUZA e SANDI, 2001) e considerando-se a utilidade dos mesmos, perda significativa de potencial econômico.

As características clássicas do fruto em questão englobam principalmente uma forma ovóide ou globosa, casca amarelada no geral e tamanho variável. O maracujazeiro dessa espécie possui flores brancas e roxas e folhas de aparência larga, além disso na produção é necessário o uso de um suporte, visto que seu caule semi lenhoso não permite autossustentação (CROCHEMORE et.al, 2003).

O maracujá-amarelo por si só possui comprovadamente efeitos ansiolíticos (SENA et.al, 2009) e até mesmo potencial antioxidante (ZERAIK, 2011). Além disso, também possui um constituinte de extrema importância, sendo provavelmente a propriedade com maior impacto biológico: a presença de pectina.

A pectina é uma fibra hidrossolúvel formada por diversas subunidades de ácido galacturônico, sendo assim eficientemente um polissacarídeo. A prática de extração das pectinas demonstrou ainda variações nas suas propriedades de acordo com a fonte (YAPO, 2007), isso serviu de parâmetro para a descoberta de outras substâncias presentes nas ramificações da molécula, como xiloses, arabinoses e ramnoses. Ela possui propriedades geleificantes que variam de acordo com o grau de metoxilação das carboxilas na cadeia, podendo assim haver uma produção controlada de acordo com o objetivo na hora de adicioná-la em produtos alimentícios. Outra propriedade extremamente importante dessa fibra é a formação de géis no intestino em conjunto com a água, o que acarretará em uma baixa absorção de gorduras da alimentação e diminuição dos níveis principalmente de colesterol e triglicerídeos, além de dar uma sensação maior de saciedade (FOOD INGREDIENTS BRASIL, 2014).

Segundo dados da EMBRAPA (2016), o Brasil vem se destacando como produtor mundial do fruto de maracujá, com uma produção de aproximadamente 1 milhão de toneladas. Dados mais recentes do Sebrae apontam uma produção em média de 12 a 15 t/ha/ano podendo este número se elevar até mais ou menos 30 a 35 t/ha/ano em áreas mais irrigadas.

O cultivo possui algumas particularidades, principalmente em virtude da necessidade de regiões pouco úmidas, incidência solar de pelo menos 11 horas ao dia e ausência de ventos fortes ou geadas. Obviamente com isso em mente podemos dizer que a produção se concentra em áreas seletas do país, principalmente nas regiões Nordeste e partes do Sudeste, apesar de haver produção em diversos outros pontos de forma mais 
escassa e espaçada. A colheita em geral dura um período de aproximadamente 6 a 9 meses, momento ótimo para a safra. Contudo, é importante citar aqui que não há produção permanente, sendo que o rendimento das colheitas vai caindo de acordo com o envelhecimento do cultivo. Assim, foi elaborado que a cada dois ou três anos as plantas sejam retiradas e o solo preparado para uma nova lavoura (SEBRAE, 2016).

O fruto do maracujá então corresponde a um produto versátil, cujo uso principal em questão de exportação e consumo interno é exatamente a produção do suco utilizando a polpa. A exportação do fruto em si é um pouco prejudicada, principalmente se tratando do envio aos EUA, por conta das barreiras fitossanitárias impostas que tornam-se cada vez mais exigentes (EMBRAPA, 2006).

Entretanto esses são apenas os usos convencionais das partes do maracujá. Como objetiva e apresenta este trabalho, a produção de massas usando a farinha da casca também é possível, caracterizando assim suas propriedades funcionais em um alimento consumido em larga escala pelo mundo (OLIVEIRA e SPANHOLLI, 2009).

O macarrão é uma massa extremamente antiga de origem duvidosa. Uma teoria amplamente divulgada pressupõe que a receita do macarrão foi trazida da China para a Itália por Marco Polo em suas infames viagens no século XIII. Isso parece ser confirmado principalmente pela presença do alimento em algumas tumbas chinesas que foram construídas na época pré-cristã. Em contrapartida, em tumbas italian datadas do período pré romano foram encontrados equipamentos perfeitos para a confecção da massa, sugerindo assim, que o prato era servido e degustado em pontos diferentes do globo, sem uma origem clara (LÓPEZ, 2017).

O macarrão pode diferir no formato, tamanho, podendo ou não levar recheio (como exemplos o Raviolli, Fettuccine e Spaghetti). Possuem estes tipos em comum a confecção básica da massa, que se constitui em trigo, ovos e óleo (LÓPEZ, 2017).

O produto cozido pode ser então consumido diretamente ou, como é mais comum, com a presença de molhos e adicionais, caracterizando assim uma alta versatilidade e aceitação do público em geral, tanto de sabor quanto de praticidade no preparo.

Devido aos hábitos alimentares atuais e a crescente demanda por alimentos agradáveis ao paladar e ricos em propriedades funcionais e saudáveis, buscou-se a elaboração de um macarrão com potencial adaptação à esse novo estilo de vida. Esperase que o macarrão produzido conserve as características benéficas da farinha da casca do maracujá, com o adicional de poder se tornar um alimento agradável e consumido pelo público em geral, devido às utilizações diárias do macarrão convencional. 
Assim, unindo os efeitos biológicos da casca de maracujá e a utilidade e aceitação do macarrão, o presente trabalho teve como objetivo a produção artesanal de massa de macarrão enriquecida com fibra da casca de maracujá, e elaborar a tabela de composição nutricional, além de discutir acerca da eficácia do produto final.

\section{MATERIAL E MÉTODOS}

O maracujá amarelo foi obtido em comércio da região metropolitana de Curitiba, Paraná, Brasil e escolhido de acordo com as seguintes características físicas: presença ou não de injúrias, tamanho, estado aparente de maturação/cor e formato. Os frutos foram transportados ao Laboratório de Bromatologia da UFPR, lavados em água corrente por 5 minutos e secos em papel toalha. Foi realizada então a separação da casca da polpa. À partir do mesmo, foi elaborada uma farinha apenas da sua casca, e partindo desta, a formulação de uma massa de macarrão que apresente características nutricionais e organolépticas agradáveis.

\subsection{Produção da farinha}

A farinha de maracujá foi obtida pela secagem das cascas em estufa a $50^{\circ} \mathrm{C}$ por 3 dias. Os maracujás foram pesados e identificados, sendo anotadas suas características superficiais. As cascas foram higienizadas em água corrente, pesadas, cortadas e secas. Após esse processo, a casca seca foi triturada e peneirada, sendo uma parte destinada à produção do macarrão e a outra às análises de composição centesimal.

\subsection{Produção do macarrão}

Para o macarrão, seguiu-se a receita de macarrão clássico do livro de receitas Dona Benta: Comer bem (2013). Foram adicionadas aproximadamente $400 \mathrm{~g}$ de farinha, sendo desse valor 7\% referente à farinha de maracujá. A proposta inicial era fazer uma massa com $10 \%$ de adição da farinha de maracujá, como mostram Spanholi e Oliveira (2009), porém durante o preparo da massa foi evidente que a farinha da casca do maracujá altera as características da mesma, que com adição de apenas $7 \%$ já apresentava cor e cheiro característicos da farinha, estando também sua consistência diferente de uma massa caseira regular. Apesar disso a continuidade da elaboração do produto não foi prejudicada. 
Fogagnoli e Seravalli (2014) mostraram que uma adição de 5\% de farinha de maracujá já altera a composição do macarrão positivamente. Também foram adicionados à receita seis ovos e uma colher de óleo, como mostra a tabela 1.

TABELA 1: RELAÇÃO DOS INGREDIENTES DA MASSA DE MACARRÃO COM SEUS PESOS MÉDIOS

\begin{tabular}{lccc}
\hline $\begin{array}{c}\text { Quantidade (em } \\
\text { medida caseira) }\end{array}$ & Ingrediente & $\begin{array}{c}\text { Peso médio unitário } \\
\text { (por medida) }\end{array}$ & Peso total adicionado \\
\hline 5 unidades & Ovo & $57 \mathrm{~g}$ & $285 \mathrm{~g}$ \\
$\begin{array}{l}3 \text { xícaras + 2 colheres } \\
\text { de sopa }\end{array}$ & Farinha de trigo & $\begin{array}{c}\text { Xícara: } 118 \mathrm{~g} \\
\text { Colher de sopa: } 8 \mathrm{~g}\end{array}$ & $370 \mathrm{~g}$ \\
4 colheres de sopa & Farinha de maracujá & $7 \mathrm{~g}$ & $28 \mathrm{~g}$ \\
1 colher de sopa & Óleo & - & - \\
\hline
\end{tabular}

A massa foi sovada manualmente, descansou por 5 minutos dentro de saco plástico e posteriormente foi aberta e cortada no formato talharim. Após o corte, a massa foi deixada para secar a fresco por 4 dias. No quinto dia foi colocada em estufa a $105^{\circ}$ por 30 minutos e finalmente, armazenada em recipiente fechado.

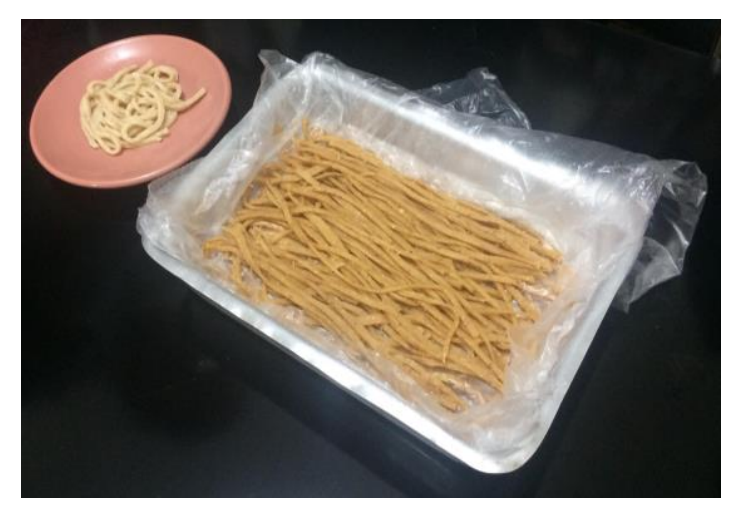

Figura 1: Aspecto da massa após ser cortada. A direita a massa crua e a esquerda a massa cozida 


\subsection{Análise centesimal}

As análises seguintes foram realizadas em ambos os materiais (farinha e macarrão), sendo que para isso o macarrão precisou ser triturado após a secagem. 0 macarrão não foi cozido, sendo ao final dos cálculos adicionado um fator de cozimento.

Para determinar umidade, lipídios e minerais, utilizou-se as metodologias propostas pelo Instituto Adolfo Lutz (2008). Já para as determinações de proteínas e fibras, utilizouse o descrito por Association of Official Agricultural Chemists (AOAC), em 1995 e 1970, respectivamente. O processo prático da determinação de proteínas seguiu a metodología de Kjedahl, sendo utilizado o fator de conversão em proteínas de 6,25 para o macarrão de 5,75 para a casca, conforme o descrito pela RDC nํ 360/03 da ANVISA (BRASIL, 2003).

Para obtenção do valor correspondente a carboidratos, foi realizado cálculo de NIFEXT, ou método da determinação de carboidratos por diferença (RDC 360, 2003).

\subsection{Análise das características organolépticas do macarrão}

As características organolépticas foram avaliadas por um grupo de 11 voluntários que tiveram acesso ao produto cozido e cru, e avaliaram pontos como cor, odor, sabor e textura, atribuindo notas de 1 a 4 , sendo o 1 correspondente á ruim e o 4 a ótimo. A avaliação se deu com a repartição de amostras da massa tanto crua quanto cozida, por 10 minutos, em pratos plásticos, apresentados então aos provadores, sendo estes alunos que frequentavam a aula de bromatologia para farmácia no mesmo período que os idealizadores.

O local de degustação foi o laboratório de Bromatologia do setor de farmácia da UFPR, Campus jardim botânico pelo período da manhã (aproximadamente às 09:00 horas). Os voluntários se dividiram em seus locais usuais nas duas bancadas do local e deram então suas notas para os quesitos já citados acima.

\section{RESULTADOS E DISCUSSÕES}

Concluídas as análises específicas, podem ser levantadas algumas hipóteses e afirmações acerca da eficácia do produto. Os resultados para composição química e centesimal obtidos são apresentados na tabela abaixo: 
TABELA 2: RESULTADO OBTIDO DA COMPOSIÇÃO QUÍMICA E CENTESIMAL DO MACARRÃO E FARINHA DA CASCA DE MARACUJÁ

\begin{tabular}{|c|c|c|c|c|}
\hline Determinação & $\begin{array}{c}\text { Casca do } \\
\text { maracujá (100g) }\end{array}$ & $\begin{array}{l}\text { Farinha da casca } \\
\qquad(100 \mathrm{~g})\end{array}$ & $\begin{array}{l}\text { Macarrão cru } \\
\qquad(100 \mathrm{~g})\end{array}$ & $\begin{array}{c}\text { Macarrão cozido } \\
(100 \mathrm{~g})^{\star \star}\end{array}$ \\
\hline Umidade & $89,21( \pm 0,55)$ & $10,52( \pm 0,67)$ & $16,61( \pm 0,03)$ & 31,52 \\
\hline Proteínas ${ }^{* *}$ & $0,42( \pm 0,003)$ & $3,89(--)$ & $18,62( \pm 0,12)$ & 6,58 \\
\hline Lipídios & $0,05( \pm 0,008)$ & $0,51( \pm 0,08)$ & $7,81( \pm 0,41)$ & 2,76 \\
\hline Carboidratos* & 5,17 & 37,44 & 49,39 & 17,45 \\
\hline Fibras & $4,61( \pm 0,46)$ & $42,71( \pm 4,24)$ & $6,53( \pm 0,1)$ & 2,31 \\
\hline Minerais & $0,53( \pm 0,04)$ & $4,93( \pm 0,40)$ & $1,03( \pm 0,07)$ & 0,36 \\
\hline Kcal & 22,81 & 169,91 & 342,33 & 120,96 \\
\hline
\end{tabular}

*Obtido pelo método da diferença (NIFEXT).

${ }^{* *}$ Fator de cocção igual 2,83 (ANJOS, 20--).

${ }^{* * *}$ Fator de conversão para proteínas de 6,25 para o macarrão e 5,75 para a casca.

Pode-se observar que valores obtidos nas determinações condizem com os valores encontrados em literatura. Por exemplo, a farinha da casca do maracujá (Passiflora edulis f. flavicarpa deg. - Família Passifloraceae) apresentou um valor centesimal de 42,71 gramas de fibras, o que já a caracteriza como uma ótima fornecedora de fibras (ANVISA), ao passo que valores como o de lipídios foram relativamente pequenos, em torno de 0,05 gramas. Isso fornece a ela uma habilidade importante que é a possibilidade de adicionar as características benéficas de fibras à alimentos que não as possuam (JANEBRO et. al., 2008), sem alterar muito a quantidade de gorduras do produto.

Desse modo, a casca do maracujá pode ser usada na forma de farinha como fonte de fibras na alimentação, sendo que sua incorporação na formulação de alimentos deve atentar às suas características físicas, químicas e sensoriais, para garantir seu melhor aproveitamento e aceitação entre os consumidores (CAZARIN et. al., 2014). 
Nesse estudo, não foi avaliado o perfil de fibras presente na farinha, porém Córdova et. al. (2005), ao traçar o perfil de fibras presentes na casca do maracujá, constataram maior teor de fibras solúveis, em especial a pectina, o que permite a suposição de que tanto a farinha quanto o alimento contendo a mesma preservam essa característica. Então, podese supor que ambos produtos possuam a característica de geleificação do bolo alimentar no estômago, promovida pelo alto teor de fibras solúveis.

Um possível uso clínico é a possibilidade de redução do colesterol a partir da suplementação de farinha da casca do maracujá na alimentação diária, como constataram Ramos et. al. (2007), que observaram a redução nos níveis de colesterol total e LDL ao trabalhar com dezenove mulheres apresentando hipercolesterolemia, tratadas com $30 \mathrm{~g}$ de farinha por dois meses.

$\mathrm{Na}$ formulação da massa com adição de farinha de casca de maracujá feita nesse estudo obteve-se a seguinte tabela de informação nutricional:

TABELA 3: INFORMAÇÃO NUTRICIONAL FARINHA DA CASCA DO MARACUJÁ E MACARRÃO OBTIDO COM ESSA FARINHA NA PORÇÃO DE 28G E 110 G, RESPECTIVAMENTE

\begin{tabular}{lcccc}
\hline Informação & $\begin{array}{c}\text { Farinha da casca } \\
(\mathbf{2 8 g})^{\star \star \star}\end{array}$ & VD\%* $^{*}$ & $\begin{array}{c}\text { Macarrão cozido } \\
(\mathbf{1 1 0 g})^{\star *}\end{array}$ & VD\%* \\
\hline Valor Energético & $47,5748 \mathrm{Kcal}$ & 2,38 & $133,0560 \mathrm{Kcal}$ & 6,65 \\
Carboidratos & 10,4832 & 3,4944 & 19,195 & 6,4 \\
Proteínas & 1,0892 & 1,4523 & 7,238 & 9,65 \\
Lipídios & 0,1428 & 0,2596 & 3,036 & 5,52 \\
Fibras & 11,9588 & 47,8352 & 2,541 & 10,16 \\
\hline
\end{tabular}

${ }^{*}$ Segundo RDC 360/03, para um VD\% $=2000$ Kcal (BRASIL, 2003)

${ }^{* *}$ Correspondente a medida caseira de um pegador (PINHEIRO et. al., p. 40, 2004 ).

${ }^{* * *}$ Correspondente a 4 colheres de sopa.

Fogagnoli e Seravalli (2014), em seu estudo sobre a aplicação de farinha de casca de maracujá em massas alimentícias, consideraram como uma boa fonte de fibras sua 
formulação de $5 \%$ de farinha de maracujá, que apresentou 2,5 g de fibras em uma porção de $80 \mathrm{~g}$ de macarrão. Assim, o macarrão obtido a partir de substituição de $7 \%$ da farinha de trigo pela farinha da casca do maracujá se mostrou uma importante fonte de fibras, visto que uma porção de $110 \mathrm{~g}$ do macarrão cozido apresenta aproximadamente 2,5 g, cerca de $10 \%$ das necessidades diárias (tabela 3 ).

Em comparação com composição centesimal do macarrão cru com trigo e ovos da Tabela Brasileira de Composição de Alimentos (TACO), a massa crua com 7\% de farinha de casca de maracujá (tabela 2) apresenta mais que o dobro em fibras, 6,5 g em comparação com 2,3 g. A quantidade de carboidratos diminui na formulação com a farinha da casca de maracujá, sendo 49,4 g em comparação com 77 g no macarrão padrão. Por comparação, comprova-se a eficácia do produto obtido considerando o aumento perceptível no teor de fibras e diminuição de carboidratos. Além disso, a quantidade de proteínas também é maior no macarrão produzido com farinha de casca de maracujá, sendo cerca de 18,6 g. Esse dado pode também ser proveniente da receita base escolhida, que previa adição de 5 ovos. Como não há informações sobre a receita base do macarrão da tabela TACO, esse resultado passa a ser inconclusivo.

TABELA 4: COMPOSIÇÃO CENTESIMAL TACO PARA MACARRÃO CRU COM TRIGO E OVOS (100G)

\begin{tabular}{lc}
\hline Umidade & $\mathbf{1 1 \%}$ \\
\hline Kcal & 371 \\
Proteína $(\mathrm{g})$ & 10 \\
Lipídeos $(\mathrm{g})$ & 2 \\
Carboidrato $(\mathrm{g})$ & 77 \\
Fibras $(\mathrm{g})$ & 2,3 \\
\hline
\end{tabular}

Com relação à aceitação do produto, pode-se observar que foi obtido um valor que remete ao menos a uma aprovação mediana (tabela 5). Em ambas as apresentações do macarrão (cru ou cozido) a menor nota proporcionalmente se observou na aparência do produto, isso pode ter ocorrido devido ao formato irregular e amarelado da massa crua ou 
à consistência esbranquiçada e um pouco rugosa observada após a cocção. O odor do macarrão cozido, mesmo sem adição de óleo, obteve uma marca de $45 \%$ dos votos na nota máxima, sendo esse valor de $63 \%$ na nota 3 quando o produto se apresenta cru. Estes dados reforçam a aceitação.

O sabor de ambos também obteve resultados positivos, ainda que bem distribuídos nas notas 2, 3, e 4 na massa crua, sugerindo que o sabor residual amargo, que é comum em formulações com alta quantidade da farinha (OLIVEIRA e SPANHOLLI, 2009) não foi encontrado ou ao menos percebido pelos participantes, indicando assim uma boa escolha quando se refere à proporção de farinhas na receita. A distribuição nas notas da massa crua, quase equilibrada, pode ser devido à estranheza dos degustadores em experimentar um produto classicamente ingerido cozido.

A textura analisada no macarrão cozido também apresentou ampla aceitação, com $63 \%$ na nota 3 , em contraste com os valores obtidos na aparência.

TABELA 5: AVALIAÇÃO DAS CARACTERÍSTICAS ORGANOLÉPTICAS DO MACARRÃO PRODUZIDO A PARTIR DA FARINHA DA CASCA DO MARACUJÁ (EM QUANTIDADE DE MARCAÇÕES POR ESCALA DE AVALIAÇÃO)

\begin{tabular}{|c|c|c|c|c|c|c|c|c|}
\hline & \multicolumn{4}{|c|}{ Macarrão Cru } & \multicolumn{4}{|c|}{ Macarrão cozido } \\
\hline $\begin{array}{l}\text { Escala de } \\
\text { avaliação }\end{array}$ & 1 & 2 & 3 & 4 & 1 & 2 & 3 & 4 \\
\hline Aparência & 0 & $\begin{array}{c}6 \\
(54 \%)\end{array}$ & 4 & 1 & 1 & $\begin{array}{c}5 \\
(45 \%)\end{array}$ & 3 & 2 \\
\hline Odor & 0 & 0 & $\begin{array}{c}7 \\
(63 \%)\end{array}$ & 4 & 0 & 1 & 5 & $5(45 \%)$ \\
\hline Sabor & 0 & 3 & 4 & $\begin{array}{c}4 \\
(36 \%)\end{array}$ & 0 & 2 & $\begin{array}{c}7 \\
(63 \%)\end{array}$ & 2 \\
\hline Textura & -- & -- & -- & -- & 1 & 3 & $\begin{array}{c}6 \\
(54 \%)\end{array}$ & 1 \\
\hline
\end{tabular}




\section{CONSIDERAÇÕES FINAIS}

Devido ao alto teor de fibras o macarrão com a adição de $7 \%$ de farinha de maracujá, o produto pode ser considerado como uma alternativa mais saudável para o consumo de massas alimentícias. A adição da farinha da casca de maracujá atribuiu ao produto uma característica funcional, que permite uma possível diminuição da absorção dos carboidratos e da gordura presente no macarrão e no bolo alimentar. Sensorialmente, o produto também apresentou bons resultados, sendo um importante parâmetro comercial para a aceitação do público que procura uma alternativa saudável, porém sem grandes diferenças nas características organolépticas quando comparado ao macarrão tradicional.

\section{REFERÊNCIAS}

ANJOS, M. C. Relação de fatores de correção e índice de conversão (cocção) de alimentos. Disponível em: <https://docs.ufpr.br/ monica.anjos/Fatores.pdf> Acesso em: 6 nov. 2017.

A.O.A.C. ASSOCIATION OF OFFICIAL AGRICULTURAL CHEMISTS. Official Methods of Analysis. 12th ed. USA: ASSOCIATION OF OFFICIAL AGRICULTURAL CHEMISTS, Washington D.C. 1970. 1094 p.

A.O.A.C. ASSOCIATION OF OFFICIAL AGRICULTURAL CHEMISTS. Official Methods of Analysis. USA: ASSOCIATION OF OFFICIAL AGRICULTURAL CHEMISTS, Washington D.C. 1995.

BRASIL, Anvisa. Alimentos enriquecidos. Agência Nacional de Vigilância Sanitária Anvisa. Disponível em <http://portal.anvisa.gov.br/resultado-de-busca?p_p_id=101\&p_p_ lifecycle $=0 \& p \_p \_s t a t e=m a x i m i z e d \& p \_p \_m o d e=v i e w \& p \_p \_c o l i d=c o l u m n-1 \& p \_p \_c o l$ count=1\&_101_struts_action=\%2Fasset_publisher\%2Fview_content\&_101_assetEntryld= 2866865\&_101_type=content\&_101_groupld=219201\&_101_urlTitle=alimentos-enriquecidos\& \&inheritRedirect=true>. Acesso em: 6 nov. 2017.

BRASIL, Anvisa. Resolução RDC no 360, de 23 de dezembro de 2003. Ministério da Saúde - MS. Agência Nacional de Vigilância Sanitária - Anvisa. Disponível em: < http://www.anvisa.gov.br>. Acesso em: 6 nov. 2017. 
BRASIL, F. I. Pectinas: propriedades e aplicações. Food Ingredients Brazil, p. 46-53, 2014. Disponível em: <http://revista-fi.com.br/upload_arquivos/201606/2016060026332001 1464897653.pdf>. Acesso em 06 nov. 2017.

CAZARIN, C. B. B.; SILVA, J. K.; COLOMEU, T. C; ZOLLNER, L. R.;MARÓSTICA, M. R. J. Capacidade antioxidante e composição química da casca de maracujá (Passiflora edulis). Cienc. Rural, Santa Maria, v. 44, n. 9, p. 1699-1704, set. 2014. Disponível em <http://www.scielo.br/scielo.php?script=sci_arttext\&pid=S0103-84782014000901699\&lng= pt\&nrm=iso >. Acesso em: 06 nov. 2017.

CÓRDOVA, K. R. V.; GAMA, T. M. M. T. B.; WINTER, C. M. G.; NETO, G. K.; FREITAS, R. J. S. Características físico-químicas da casca do maracujá amarelo (Passiflora edulis Flavicarpa Degener) obtida por secagem. Centro de Pesquisa e Processamento de Alimentos, v. 23, n. 2, jul./dez. 2005. Disponível em: http<://revistas.ufpr.br/alimentos/ article/viewFile/4491/3497>. Acesso em: 6 de nov. 2017.

CROCHEMORE, M. L.; MOLINARI, H. B.; MARIA, N.; STENZEL, C. Caracterização agromorfológica do maracujazeiro (Passiflora spp.) Revista Brasileira de Fruticultura, v. 25, n. 1., p. 5-10, 2003. Disponível em: <http://www.scielo.br/pdf/rbf/v25n1/a04v25n1.pdf>. Acesso em: 2 out. 2017.

Evolução do maracujazeiro-amarelo no Brasil, as principais doenças e possibilidade de aplicação do controle biológico. EMBRAPA. Disponível em: <https://www.embrapa.br/documents/1355163/2022525/doc203.pdf/2de8237d-b503-4bbc94ce-1f90c0f13b8a >. Acesso em: 2 out.2017.

FOGAGNOLI, G., SERAVALLI, E. A. G. Aplicação de farinha de casca de maracujá em massa alimentícia. Brazilian Journal of Food, v. 17, n. 3, p. 204-212, jul./set. 2014. Disponível em: <http://www.scielo.br/scielo.php?script=sci_arttext\&pid=S1981-672320140 $00300004 \&$ Ing=pt\&tlng=pt>. Acesso em: 2 out. 2017.

IAL. Instituto Adolfo Lutz. Normas analíticas do Instituto Adolfo Lutz: métodos químicos e físicos para análise de alimentos. São Paulo: Instituto Adolfo Lutz 2008. 1020p. 
JANEBRO, D. I.; QUEIROZ, M. R.S.; SABAA-SRUR, A. U. O.; CUNHA, M. A. L.; RAMOS, A.T.; DINIZ, F. M. Efeito da farinha da casca do maracujá-amarelo (Passiflora edulis $f$. flavicarpa Deg.) nos níveis glicêmicos e lipídicos de pacientes diabéticos tipo 2. Revista Brasileira de Farmacognosia, v. 18, p. 724-732, 2008. Disponível em: <http://www.scielo. br/scielo.php?pid=S0102-695X2008000500016\&script=sci_abstract\&tlng=pt>. Acesso em: 6 nov. 2017.

OLIVEIRA, V. F., SPANHOLI, L. Utilização de farinha de albedo de maracujá (Passiflora edulis flavicarpa degener) no preparo de massa alimentícia. Disponível em: <http://servbib.fcfar.unesp.br/seer/index.php/alimentos/article/view/1237/864>. Acesso em: 2 out. 2017 O cultivo e o mercado do maracujá. SEBRAE. Disponível em: <https://www.sebrae.com.br/ sites/PortalSebrae/artigos/o-cultivo-e-o-mercado-do-maracuja,108da5d3902e2410Vgn VCM100000b272010aRCRD>. Acesso em: 2 out. 2017.

PINHEIRO, A. B. V., LACERDA, E. M. A., BENZECRY, E. H., GOMES, M. C. S., CASTRO, V. M. Tabela para avaliação de consumo alimentar em medidas caseiras. p. 40. Editora: Atheneu, 4ํㅡㄹ. edão Paulo, 2004.

RAMOS, A. T.; et al. Uso de Passiflora edulis f. flavicarpa na redução do colesterol. Rev. bras. farmacogn., João Pessoa, v. 17, n. 4, p. 592-597, Dec. 2007. Disponível em: $<$ http://www.scielo.br/scielo.php?script=sci_arttext\&pid=S0102-695X2007000400019\&lng= en\&nrm=iso>. Acesso em 06 Nov. 2017

SCHULZE, M. B.; LIU, S.; RIMM, E. B.; et al. Glycemic index, glycemic load, and dietary fiber intake and incidence of type 2 diabetes in younger and middle-aged women. American Journal of Clinical Nutrition, n. 10, p. 348-356, 2004. Disponível em: <http://nutrigen.ph. ucla.edu/files/view/pubs/04gly-load-fiber-women.pdf>. Acesso em: 6 nov. 2017.

SENA, M. L; ZUCOLOTTO, M. S; REGINATTO, F. H.; SCHENKEL, E. P; LIMA, T. C. M. Neuropharmacological activity of the pericarp of Passiflora edulis flavicarpa Degener: Putative involvement of $C$-Glycosylflavonoids. Experimental Biology and Medicine. $\mathrm{n}$. 234, p. 967-975,2009. Disponível em: <https://www.researchgate.net/publication/26261939 _Neuropharmacological_Activity_of_the_Pericarp_of_Passiflora_edulis_flavicarpa_Degen er_Putative_Involvement_of_C-Glycosylflavonoids>. Acesso em: 6 nov. 2017. 
SOUZA, A.C.G.; SANDI, D. Industrialização. Brückner, C. H.; PICANÇO, M. C. Maracujá: tecnologia de produção pós colheita, agroindústria e mercado. Porto Alegre: Cinco continentes, 2001. 472p.

The twisted history of pasta. National Geographic. Disponível em: <http://www.nationalgeographic.com/archaeology-and-history/magazine/2016/07-08/dailylife-pasta-italy-neapolitan-diet/>. Acesso em: 2 out. 2017.

UNICAMP. Tabela Brasileira de Composição de Alimentos, TACO. NEPA-UNICAMP, 4 ed., 161p., 2011. Disponível em: <http://www.cfn.org.br/wp-content/uploads/2017/03/taco_ 4_edicao_ampliada_e_revisada.pdf $>$. Acesso em: 2 out. 2017

ZERAIK, M. L.; SERTEYN, D.; DEBY-DUPONT, G.; WAUTERS, M. T.; YARIWAKE, J. H.; ANGENOT, L.; FRANK, T. Evaluation of the antioxidant activity of passion fruit (Passiflora edulis and Passiflora alata ) extracts on stimulated neutrophils and myeloperoxidase activity assays. Food Chemistry, v. 128, n. 2, p. 259-265, 2011. Elsevier Ltd. Disponível em: <http://dx.doi.org/10.1016/j.foodchem.2011.03.001>. Acesso em: 2 out. 2017. 